\title{
A RELAÇÃO ENTRE A REMUNERAÇÃO EXECUTIVA E O DESEMPENHO DE COMPANHIAS DO SETOR DE SAÚDE: UMA VISÃO APÓS ADOÇÃO DAS NORMAS CPC PME
}

Juliano Augusto Orsi De Araujo ${ }^{1}$

Maisa Souza Ribeiro ${ }^{1}$

Marcelo Botelho Da Costa Moraes ${ }^{1}$

${ }^{1}$ Universidade de São Paulo 


\section{A RELAÇÃO ENTRE A REMUNERAÇÃO EXECUTIVA E O DESEMPENHO DE COMPANHIAS DO SETOR DE SAÚDE: UMA VISÃO APÓS ADOÇÃO DAS NORMAS CPC PME}

Resumo: Neste artigo investigamos a relação entre a remuneração de executivos e o desempenho de 470 empresas do setor de saúde no Brasil, obtidos por meio de informações contábeis, obtidas junto à Agência Nacional de Saúde Suplementar - ANS no período de 2012 a 2016. O estudo se justifica pelo fato de o Estado atender apenas $43 \%$ dos gastos no setor de saúde e a iniciativa privada os $57 \%$ restantes, sendo $34 \%$ por meio de gastos diretos privados e $23 \%$ por meio de planos de saúde. Foram analisados o impacto dos indicadores ROE, ROA e o Lucro. Não encontramos relação estatística entre o ROE e a remuneração executiva. O ROA apresentou significância estatística, porém negativa, o que indicou que ambos os indicadores não são utilizados para determinar as políticas de remuneração no setor. O Lucro apresentou significância estatística positiva, porém fraca, também com pouco impacto sobre os pacotes de remuneração. Conclui-se que os pacotes de remuneração são maiores em empresas de maior porte.

Palavras-chave: Remuneração Executiva. Saúde no Brasil. Retorno. Desempenho. 


\section{Introdução}

Neste artigo investigamos a relação entre a remuneração de executivos e o desempenho de empresas do setor de saúde no Brasil. Os sistemas de remuneração apresentam-se como uma ferramenta de alinhamento de interesses de gestores e proprietários de empresas, a fim de diminuir conflitos de agência. Sá, Maciel e Reinaldo (2017) alertam para o crescente número de operadoras de saúde que entram em estado de solvência no Brasil. Os autores apontam fatores que levam as empresas a esta condição, dentre as quais destacam-se transição demográfica, transição epidemiológica, novas tecnologias, seleção adversa, risco moral, reajuste do valor pago pela assistência à saúde, controle de reajustes das mensalidades, judicialização da saúde e o amplo arcabouço legal e regulatório que impõe às operadoras várias obrigações e limitam a adoção de diversas estratégicas.

Neste sentido, oferecer sistemas de remuneração a executivos como parte da estratégia da companhia para o alinhamento de interesses entre gestores e acionistas surge como uma proposta de minimizar perdas à entidade e maximizar o desempenho da entidade. $\mathrm{O}$ conflito de interesses existente entre acionistas e executivos é clássico e tratado pela Teoria da Agência. Em suma, se os acionistas possuíssem as informações plenas das atividades da companhia, perspectivas de investimentos e as ações dos próprios executivos, conseguiriam estabelecer um contrato em que poderiam maximizar o retorno para si mesmos. No entanto, não possuem tais informações e o problema surge quando da diferença existente entre os interesses dos executivos (agentes) e os seus próprios (acionista, o principal).

Logo, acionistas procuram estabelecer maneiras de alinhar seus interesses aos dos executivos por meio de contratos em que haja a maximização da função utilidade para ambos os lados. Nestas situações, a Teoria da Agência prediz que as políticas de remuneração são estabelecidas para fornecer incentivos aos executivos de modo que estes elejam e tomem as decisões que maximizam a riqueza para o acionista.

O segmento de saúde no Brasil é suprido por meio de governos e iniciativa privada, tal que nesta última identificam-se entidades de: i-) filantropia; ii-) medicina em grupo; iii-) cooperativas médicas; iv-) entidades de autogestão; v-) administradoras de benefícios e; vi-) seguradoras especializadas. Segundo IBGE (2017) o poder público responde por $43 \%$ dos gastos no setor e a iniciativa privada pelos $57 \%$ restantes, sendo $34 \%$ por meio de gastos diretos privados e $23 \%$ por meio de planos de saúde. No país, aproximadamente 800 empresas são responsáveis pelo atendimento a 47,5 milhões de beneficiários de planos médico-hospitalares. Juntas, segundo dados divulgados pela Agência Nacional de Saúde Suplementar (2017) movimentam mais de $\mathrm{R} \$ 130$ bilhões por ano.

Assim, o objetivo da pesquisa é verificar se há relação entre os incentivos financeiros oferecidos aos gestores e o desempenho das entidades do setor de saúde brasileiro, que prestaram contas junto à Agência Nacional de Saúde Suplementar - ANS no período de 2012 a 2016.

Os estudos acerca de remuneração surgem quando da percepção de que existem altos pagamentos aos gestores (JENSEN; MURPHY, 1990a; CONYON; LEECH, 1994; CONYON; GREGG, 1994; CONYON, 1997) provocando inquietação quanto à discrepância com os salários dos demais colaboradores das companhias, que podem variar de 13 a 80 vezes. Os autores entendem que a remuneração é inadequada. Em função desta discrepância, os autores sugerem maior disclosure acerca da remuneração executiva.

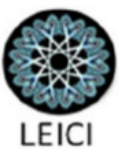


Estudos como de Murphy (1985), Jensen e Murphy (1990a) e Conyon e Gregg (1994) encontraram relação da remuneração executiva com o incremento de vendas, sugerindo assim um monitoramento inicial por parte dos acionistas por meio de metas de vendas. Os estudos de Jensen e Murphy (1990a), Conyon e Leech (1994), Conyon e Gregg (1994) e Conyon (1997) não encontraram forte relação entre remuneração e desempenho das companhias.

No Brasil a divulgação de informações que permitem o estudo de remuneração executiva deu-se a partir de 2009, com a normativa editada pela Comissão de Valores Mobiliários. No entanto, ao restringir-se à área de saúde, tais informações podem ser obtidas por meio do portal da Agência Nacional de Saúde Suplementar, a ANS, com dados publicados a partir de 1992.

\section{Referencial teórico}

\subsection{Teoria da agência}

Os estudos voltados a investigar a relação entre a remuneração executiva e o retorno para os acionistas derivam da pesquisa de Jensen e Meckling (1976) que, a partir de elementos da Teoria da Agência, da Teoria dos direitos de propriedade e da Teoria de Finanças, desenvolveram a Teoria de estrutura de propriedade da firma. Os autores definiram os conceitos de custos de agência e sua natureza.

Jensen e Meckling (1976) questionam se a Teoria da Firma é uma caixa vazia, dado que ela é impulsionada pelo mercado, que por sua vez é repleto de firmas que, segundo os autores, são verdadeiras caixas pretas no que tange à divulgação de informações relevantes ao mercado no qual estão inseridas. Para eles, o problema se estende desde os estudos de Adam Smith e Alfred Marshall e uma questão ainda não esclarecida é o equilíbrio entre os interesses dos participantes do mercado. Acreditam que maximizar a função utilidade para todas as partes é o caminho a ser seguido. $\mathrm{O}$ estudo permeia a discussão acerca do direito de propriedade, os custos de agência e discussões gerais sobre a definição de firma.

Jensen e Meckling (1976) definem a relação de agência como um contrato sob o qual uma ou mais pessoas (principal) engajam ou delegam a uma terceira pessoa (agente) que consiste na delegação de tomada de decisões que impactam diretamente na propriedade do principal. Se neste contrato, a função utilidade for maximizada para ambas as partes, há razões suficientes para crer que o agente nem sempre tomará as melhores decisões a favor do principal. E ainda, o principal empenhará recursos para garantir que o agente não tomará certas decisões contrárias aos seus interesses.

No entanto, é impossível para o principal garantir que se cercou de todas as medidas e cuidados que garantirão a melhor ação do agente a seu favor. Assim, nas relações de agência, agente e principal incorrerão em gastos de monitoramento, que podem ou não ser pecuniários e ainda assim podem existir conflitos em função da decisão tomada pelo agente. Nesse sentido, surgem os custos de monitoramento ou custos de agência.

Os conflitos entre principal e agente afetam as funções principais da empresa, tais como, investimentos e políticas financeiras, que podem resultar em perdas para o acionista (BYRD; PARRINO; PRITSH, 1998). Apesar do agente ser contratado pelo principal, face sua capacidade e características profissionais de ponta, este não toma as decisões que o próprio acionista tomaria (JENSEN; MURPHY; WRUCK, 2004). Sob esta ótica, Byrd, Parrino e Pritsh

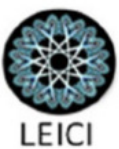


(1998) apresentam no quadro 1 os problemas de agência mais comuns apresentados na literatura:

\section{QUADRO 1 - Tipos de problemas de Agência}

Problema

Esforço

Horizonte

Preferências em

relação ao risco

Uso de Ativos

\section{Definição}

Executivos percebem incentivos para exercer um esforço muito menor do que a expectativa de acionistas.

Executivos observam um horizonte em termos temporais muito menor para realizar os resultados dos investimentos do que os acionistas teriam.

Fonte: Adaptado de Byrd, Parrino e Pritsh (1998)

Existem alguns mecanismos de diminuir este conflito entre agente e principal, dentre os quais a política de remuneração pode fornecer incentivos ao aumento do valor, incluindo bônus baseados em desempenho e revisões salariais, opções de ações e remuneração com base no desempenho.

\subsection{Remuneração executiva}

Conyon (1997) afirma que a remuneração por meio do salário busca compensar o executivo pela responsabilidade. Cordeiro e Veliyath (2003) complementam tal afirmação chamando a atenção para o risco, os esforços e a complexidade das operações da companhia sob responsabilidade do executivo. Assim, Murphy (1998) acredita que o salário base de executivos é, em geral, fixado por um benchmarking competitivo, norteado por pesquisas salariais gerais, agregando-se análise de segmento ou setor econômico da empresa. Contudo este parâmetro tem sido, substancialmente, substituído pelo tamanho da empresa.

Conyon e Leech (1994) afirmam que a remuneração executiva é empiricamente influenciada pelo tamanho da companhia uma vez que o impacto de decisões erradas de um executivo numa grande empresa é mais sensível do que numa de menor porte, o que leva as grandes corporações a buscar profissionais do mais alto gabarito no mercado. Não obstante, com lucros absolutos maiores, o impacto de uma maior remuneração executiva no resultado acaba sendo absorvido pelo bom desempenho da empresa.

Contudo, com esse impacto deveras pequeno no resultado, pode levar a um controle ineficiente e deficiente por parte dos investidores que, no caso das companhias americanas, se agrava pela pulverização do controle acionário. Leonard (1990) afirma que as grandes empresas possuem uma extensão hierárquica muito grande, com níveis salariais diferenciados, o que leva a grandes distorções salariais, o que, para Firth et al. (1999), pode exceder a remuneração de executivos de pequenas empresas.

Deste modo, alguns estudos apresentam resultados de relação positiva e significativa entre remuneração e tamanho das companhias. Murphy (1996) afirma que estudos econométricos apresentam a variável "tamanho da companhia" como a única determinante na remuneração de executivos. Esta variável é medida pelo total de ativos ou volume de vendas. As demais variáveis apresentam um papel menor nos estudos empíricos.

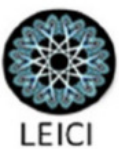


Firth et al (1999) afirmam que os acionistas, de maneira geral, avaliam o tamanho da empresa, utilizando-se de medidas de desempenho econômico para avaliar o empenho do executivo. Assim, alinham o pagamento de executivos ao desempenho da empresa, baseados na premissa de que os executivos maximizem o retorno de seus investimentos.

Murphy (1998) destaca uma outra forma também usual na remuneração executiva: planos de bônus executivo, atrelando metas à resultados. Estes planos podem ser divididos em: i) medidas de desempenho; ii) padrões de desempenho e; iii) estrutura da relação de remuneração-desempenho.

Companhias norte americanas, utilizam dois ou mais indicadores. Murphy (1998) afirma que em muitos casos as medidas são multiplicativas, tal que o pagamento do bônus pode aumentar ou diminuir em função de resultado de outros indicadores. Existem casos em que o pagamento de bônus está alinhado a uma matriz de medidas de desempenho. $\mathrm{O}$ autor afirma que aproximadamente $91 \%$ das empresas americanas contam com uma medida de lucro contábil ao menos em seus planos de bônus (MURPHY, 1998).

Firth et al. (1999) afirmam que as medidas de desempenho contábil utilizadas pelas companhias são: i) percentual nos resultados de metas; ii) percentual nas alterações dos resultados; iii) retorno sobre ativos e; iv) retorno sobre o patrimônio líquido. Para os autores, medidas de desempenho contábil mensuram divisões da empresa. Posto isto, os autores também afirmam que os executivos exercem maior controle e influência sobre estas medidas, o que faz com que sejam mais tangíveis (FIRTH et al., 1999). Para Murphy e Jensen (1990a), no entanto, o lucro contábil pode trazer informação valiosa ao avaliar as ações não observáveis dos executivos.

Contudo, dados contábeis podem ser "maquiados" ou manipulados por executivos. Este ponto é advertido por Firth et al. (1999), com corroboração de Anderson, Cavanahg e Hartman (2002) quando apresentam a expressão "contabilidade criativa". Esta linha também já era defendida por Murphy e Jensen (1990a), quando afirmavam que alinhar a remuneração executiva aos lucros contábeis ao invés de alteração na riqueza dos acionistas, gera incentivos para o sistema contábil ser manipulado diretamente. Deste modo, com a regulamentação do setor de saúde no Brasil, parte-se do pressuposto que esta contabilidade criativa não seja presente no setor.

\subsection{Saúde no Brasil}

Segundo Carvalho (2013), a saúde no Brasil passou, historicamente, pela filantropia de cunho religioso e de caridade. Paralelamente a isso, o Estado fazia algumas ações de saúde diante de epidemias, como ações de vacinação e/ou de saneamento básico. Carvalho (2013) afirma ainda que a partir de 1923, com a Lei Elói Chaves, a saúde dos trabalhadores vincula-se à previdência e passa a ser componente de um sistema para os trabalhadores. De início, as caixas de pensão, depois, os institutos e, finalmente, o INPS atual INSS.

Para Carvalho (2013), o Sistema Público de Saúde resultou de décadas de luta de um movimento que se denominou Movimento da Reforma Sanitária. Foi instituído pela Constituição Federal (CF) de 1988 e consolidado pelas Leis 8.080 e 8.142. Esse Sistema foi denominado Sistema Único de Saúde (SUS). O autor destaca a relevância pública dada à saúde declarada na CF. Afirma ainda que foram consideradas como de relevância pública tanto a saúde pública como a privada. Para Carvalho (2013), Loebel e Carmo (2016), os serviços de

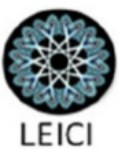


saúde prestados pelo estado não são eficientes e suficientes para o atendimento da população e necessita da suplementação por parte da iniciativa privada.

Os serviços privados de saúde, além de serem de relevância pública, estão subordinados à Regulamentação, Fiscalização e controle do SUS. Aí se incluem tanto o sistema privado com fins lucrativos, explorado por pessoas físicas ou jurídicas individuais ou coletivas, prestadoras ou proprietárias de planos, seguros, cooperativas e autogestão, quanto o sistema privado não lucrativo, filantrópico ou não. Incluem-se: hospitais, clínicas, consultórios, laboratórios bioquímicos, de imagem e outros, de todas as profissões de saúde e com todas as ações de saúde (ANS, 2017).

A partir dos anos 1990, o governo brasileiro iniciou o processo de criação de agências reguladoras para garantir a regulamentação e intervenção em diversos setores da economia, com o intuito de buscar a eficiência nos serviços básicos à população. O objetivo dessa regulação, para Firaldi et al (2016) é de preservar o equilíbrio econômico-financeiro dos regulados e garantir o acesso e a qualidade dos serviços prestados à população.

Segundo Filardi et al (2016) a comercialização de planos de saúde no Brasil ocorre desde os anos 1950. Com o aumento expressivo da demanda, em meados dos anos 1990 é que surgem as primeiras estruturas de regulamentação no setor e que nomeou de saúde suplementar, atendendo famílias e empresas. Neste momento, há uma grande migração de usuários do sistema público para o sistema privado. No entanto, as crises econômicas enfrentadas pelo país foi um grande fator que impossibilitou o crescimento do setor. Sá, Maciel e Reinaldo (2017) contribuem ao afirmar que o setor enfrenta redução de receita, aumento de custos, além de conviver com o risco atuarial envolvido.

Assim, Loebel e Carmo (2016) defendem que há preocupação eminente com as ações que visam manter a boa gestão financeira de empresas do setor de saúde e dentre estas medidas, estão inseridas as políticas de remuneração de executivos.

\section{Metodologia}

A população das entidades sob regulação da Agência Nacional de Saúde Suplementar (ANS) é composta por 1058 indivíduos. Destes, foram excluídos os que não apresentaram dados, o que levou a uma amostra de 470 indivíduos. O período de análise é de 2012 a 2016, o que proporcionou 2.350 observações. No entanto, para Brito e Martins (2013), a presença de observações extremas nas variáveis pode afetar a qualidade estatística do modelo e de suas inferências. Assim, tratou-se os dados por meio do procedimento denominado winsorização das variáveis a 5\%, substituindo as variáveis extremas pelas variáveis adjacentes (BARNETT; LEWIS, 1994):

TABELA 1 - Amostra

\begin{tabular}{lrr}
\hline $\mathbf{2 0 1 2}$ à 2016 & Amostra & Observações \\
\hline Total de Empresas & 1.058 & 5.290 \\
\hline (-) Empresas com missing values & 588 & 2.940 \\
\hline (=) Amostra final para análise & 470 & 2.350
\end{tabular}

Fonte: Os autores

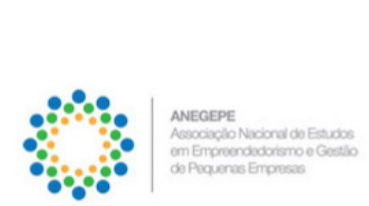

Realizadores:

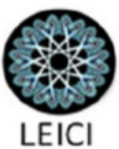


São divididos em 7 grupos, sendo: i-) filantropia; ii-) medicina em grupo; iii-) cooperativas médicas; iv-) entidades de autogestão; v-) administradoras de benefícios; vi-) seguradoras especializadas e; vii-) cooperativas odontológicas. Os dados foram extraídos da base pública disponibilizada pela ANS.

A análise inicial se deu por meio da estatística descritiva, que avaliou a composição da remuneração executiva e características das empresas. O uso da estatística descritiva no início da análise de resultados organiza, apresenta e sintetiza os dados coletados, com a finalidade de entender, relatar e discutir os dados coletados.

Contempla dados de corte transversal (i) relacionados com as características das organizações ao longo de uma série temporal (t) de 2012 a 2016, envolvendo tanto uma dimensão espacial quanto temporal, o que leva à análise de dados em painel. Preliminarmente foram realizados o teste de Heterocedasticidade, de Baum; o teste de Autocorrelação, de Wooldridge; e o teste de Multicolinearidade, que avalia a existência de relação linear entre as variáveis.

Os modelos em painel tratam a heterogeneidade dos dados e se apresentam em modelos de efeitos fixos e de efeitos aleatórios. Para eleger a especificação mais adequada, procedeu-se, primeiramente, ao teste de Lagrange Multiplier (LM), proposto por Breusch e Pagan (1980), para teste da hipótese nula dos efeitos individuais não observáveis e avaliar o fato de serem relevantes para a explicação do modelo e posteriormente decidir entre os modelos pooled e o de efeitos aleatórios. Posteriormente, foi realizado o teste de Hausman, para avaliar a correlação entre os efeitos individuais do intercepto, sob a hipótese nula de $\operatorname{corr}()=0$. Assim, caso os efeitos do intercepto não sejam correlacionados com os erros, opta-se pelo modelo de Efeitos Aleatórios; caso contrário, existindo correlação, elege-se o modelo de Efeitos Fixos.

Alguns dos dados levantados, em função da amplitude, serão tratados no modelo em logaritmo natural, o que diminui a discrepância e permite reduzir os valores extremos da série, em função da amostra apresentar heterogeneidade (BAKER; WURGLER, 2006; YOSHINAGA, 2009; ARAUJO et al, 2014).

O modelo adotado é adaptado de Gonzaga, Yoshinaga e Eid Junior (2013), o qual está a seguir apresentado:

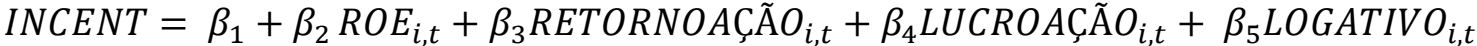

$$
\begin{aligned}
& +e_{i, t}
\end{aligned}
$$

Em que:

INCENT: Remuneração variável em razão da remuneração total, da empresa i, no período t;

ROE: Retorno sobre o patrimônio, proxy para desempenho da empresa i, no período t;

RETORNOAÇÃO: Retorno por ação, proxy para desempenho da empresa i, no período $\mathrm{t}$

LUCROAÇÃO: Lucro por ação, proxy para desempenho da empresa i, no período t;

LOGATIVO: Controle de tamanho, log do total de ativos da empresa i, no período t.

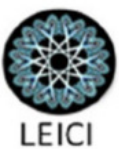


No entanto, com a limitação das informações de remuneração serem totalizadas e dadas as características das empresas que em sua maioria não são sociedades anônimas de capital aberto e também pela amostra contemplar entidades com e sem fins lucrativos, o modelo foi adaptado com o uso das seguintes variáveis:

HONDIRET: Remuneração total da diretoria, da empresa i, no período t;

ROE: Retorno sobre o patrimônio, proxy para desempenho da empresa i, no período t;

ROA: Retorno sobre o ativo, proxy para desempenho da empresa i, no período t;

LUCRO: Proxy para desempenho que mede o lucro da empresa i, no período t;

LOGATIVO: Controle de tamanho, log do total de ativos da empresa i, no período t;

FIN: Dummy constante de finalidade da entidade i, com ou sem fins lucrativos.

Deste modo, o modelo desenvolvido foi:

$$
\begin{aligned}
\text { HONDIRET }= & \beta_{1}+\beta_{2} \text { ROE }_{i, t}+\beta_{3} R_{\text {OOA }}+\beta_{4} L_{U C R O}, t+\beta_{5} \text { LOGATIVO }_{i, t}+\beta_{6} \text { FIN }_{i, t} \\
& +e_{i, t}
\end{aligned}
$$

Assim, a pesquisa verificou as seguintes hipóteses:

H1: o pacote de remuneração executiva no setor de saúde é determinado pelo ROE;

H2: o pacote de remuneração executiva no setor de saúde é determinado pelo ROA;

H3: o pacote de remuneração executiva no setor de saúde é determinado pelo resultado do exercício e;

H4: o pacote de remuneração executiva no setor de saúde é maior em empresas maiores.

Assaf Neto (2002) sugere que o uso de indicadores contábeis permite avaliar a performance de gestores por meio da análise de atratividade de investimentos e o retorno destes. Corroboram Bushman e Smith (2001) e Pukthuanthong, Talmor e Wallace (2004) quando afirmam que estas medidas de desempenho são utilizadas frequentemente para o estabelecimento de incentivos oferecidos aos gestores. Também dentro da limitação da pesquisa e dadas as características da amostra, não se elegeu medidas baseadas em informações de mercado como sugeridas por Bushman e Smith (2001). No entanto, segundo Gonzaga, Yoshinaga e Eid Junior (2013), as análises relacionadas às medidas de desempenho a serem utilizadas, independentes de sua origem, contábil ou de mercado, necessitam ser consistentes, relevantes e confiáveis e esta característica foi encontrada nos dados coletados.

Murphy (1985) e Byrd, Parrino e Pritsh (1998) recomendam o uso de características das empresas nas análises, dadas suas implicações sobre os indicadores de retorno e possíveis conflitos de agência existentes. Deste modo, utilizou-se o tamanho das companhias por meio do logaritmo natural total dos ativos e uma dummy para indicar se a entidade tem ou não fim lucrativo.

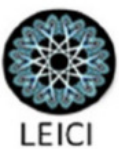




\section{Resultados}

Inicialmente os resultados apresentados com uso da estatística descritiva demonstram o comportamento das principais variáveis do estudo:

TABELA 3 - Estatística descritiva

\begin{tabular}{l|r|r|r|r|r}
\hline Variável & Obs & \multicolumn{1}{|c}{ Média } & \multicolumn{1}{c|}{$\begin{array}{c}\text { Dadrão } \\
\text { Ponvio }\end{array}$} & \multicolumn{1}{c}{ Min } & \multicolumn{1}{c}{ Max } \\
\hline HonDiret & 2.350 & $547.967,30$ & $840.959,30$ & $7.464,00$ & $7.412 .000,00$ \\
\hline ROE & 2.350 & $12,01 \%$ & $77,24 \%$ & $909,56 \%$ & $689,51 \%$ \\
\hline LOA & 2.350 & $4,66 \%$ & $10,85 \%$ & $-61,40 \%$ & $47,70 \%$ \\
\hline Ativo & 2.350 & $3.251 .825,00$ & $11.800 .000,00$ & $30.600 .000,00$ & $114.000 .000,00$ \\
\hline
\end{tabular}

Fonte: Os autores

Os dados da tabela 3 apontam para uma grande amplitude das variáveis. Ittner, Larcker e Pizzini (2007) afirmam que ao contrário dos contratos de remuneração na maioria das grandes corporações, os contratos de compensação médica tendem a apresentar variações consideráveis. Quando segregados os resultados em função da finalidade da entidade, observa-se:

TABELA 4 - Estatística descritiva por finalidade

\begin{tabular}{|c|c|c|c|c|c|}
\hline Variável & Lucro? & Média & $\begin{array}{l}\text { Desvio } \\
\text { Padrão }\end{array}$ & Min & Max \\
\hline \multirow{2}{*}{ HonDiret } & Não & $562.829,40$ & $713.815,80$ & 814,23 & $7.921 .151,00$ \\
\hline & Sim & $666.237,10$ & $2.098 .452,00$ & $3.336,00$ & $19.200 .000,00$ \\
\hline \multirow{2}{*}{ ROE } & Não & $-6,70 \%$ & $463,95 \%$ & $-16224,21 \%$ & $3675,90 \%$ \\
\hline & Sim & $68,79 \%$ & $648,78 \%$ & $-2077,01 \%$ & $10205,37 \%$ \\
\hline \multirow{2}{*}{ ROA } & Não & $4,40 \%$ & $9,55 \%$ & $-84,79 \%$ & $36,45 \%$ \\
\hline & Sim & $-57,27 \%$ & $991,74 \%$ & $-18040,51 \%$ & $175,99 \%$ \\
\hline \multirow{2}{*}{ Lucro } & Não & $2.735 .200,00$ & $17.100 .000,00$ & $297.000 .000,00$ & $375.000 .000,00$ \\
\hline & Sim & $8.874 .769,00$ & $44.600 .000,00$ & $114.000 .000,00^{-}$ & $388.000 .000,00$ \\
\hline \multirow{2}{*}{ Ativo } & Não & $64.900 .000,00$ & $170.000 .000,00$ & $131.557,90$ & $2.250 .000 .000,00$ \\
\hline & Sim & $253.000 .000,00$ & $1.340 .000 .000,00$ & 300,00 & $15.700 .000 .000,00$ \\
\hline
\end{tabular}

Fonte: Os autores

A remuneração média em entidades com fins lucrativos é maior, bem como o desvio padrão, remunerações mínimas e máximas. Nota-se também que os retornos sobre o patrimônio líquido também apresentam indicadores maiores nas entidades que visam o lucro. Os resultados 
médios, superávit ou lucro, também são maiores nas empresas com fins lucrativos, bem como os ativos aplicados. No entanto, quando negativos, os resultados são expressivos e corroboram com o que advertem Sá, Maciel e Reinaldo (2017) que apontam crescente número de operadoras de saúde que entram em estado de solvência no Brasil.

Em seguida, foi testado o modelo em mínimos quadrados ordinários onde rejeitou-se a hipótese de que todos os coeficientes são estatisticamente iguais a zero, por meio do teste "F". Pelo $\mathrm{R}^{2}$ pode-se explicar que aproximadamente $52 \%$ das variações dos honorários da diretoria podem ser explicadas pelas variáveis do modelo. No entanto, apenas a variável ROE apresentou significância estatística a 10\%:

TABELA 5 - Regressão em MQO

\begin{tabular}{l|r|r|r|r}
\hline & Coef. & Std. Err. & T & P>t \\
\hline ROE & $-78.764,05$ & $43.831,37$ & $-1,80$ & 0,072 \\
\hline ROA & $-647.683,80$ & $132.890,60$ & $-4,87$ & 0,000 \\
\hline Lucro & 0,0231435 & 0,0020629 & 11,22 & 0,000 \\
\hline LnAtivo & $155.430,00$ & $4.814,379$ & 32,28 & 0,000 \\
\hline Fin & $-150.533,70$ & $15.037,30$ & $-10,01$ & 0,000 \\
\hline Const & -2.094 .045 & $79.422,12$ & $-26,37$ & 0,000 \\
\hline \multicolumn{7}{c}{ Prob $>$ F } & 0.0000 & & & \\
\hline & R-squared & 0.5192 & & \\
\hline
\end{tabular}

Adj R-squared $=0.5182$

Fonte: Os autores

A princípio o modelo parece adequado. No entanto, é necessário verificar se o modelo não viola os pressupostos e especificações do modelo de regressão de mínimos quadrados ordinários (MQO). Por meio do teste de Shapiro-Wilk verificou-se a normalidade da distribuição dos dados. Para resultados em P>0,05 (WOOLDRIDGE, 2010), pode-se inferir que os dados possuem distribuição normal, o que é o caso.

Em seguida procedeu-se com a checagem de existência de multicolinearidade entre as variáveis. $\mathrm{O}$ modelo não demonstra a existência de multicolinearidade pois não apresentou $\mathrm{R}^{2}$ alto e tampouco valores muito baixos para a estatística t. No entanto, Wooldridge (2010) recomenda alguns procedimentos para uma melhor inferência.

O primeiro teste denominado de Teste de Fator de Inflacionamento da Variância (VIF), verifica se o valor obtido é maior que 10 , situação em que pode-se afirmar que a variável é altamente colinear. A seguir verificou-se o grau de tolerância $1 / \mathrm{VIF}$, que deve ser maior que 0,1 para que não haja multicolinearidade.

Em seguida procedeu-se com o teste Breusch-Pagan-Godfrey para verificar a heterocedasticidade. $\mathrm{O}$ teste fornece resultado com base no $\mathrm{chi}^{2}$, com hipótese nula de homocedasticidade. Com significância estatística a 1\%, o teste rejeita a hipótese nula. Também foi realizado o teste de White em que constatou-se novamente a existência de heterocedasticidade nos dados. A maneira adotada de adequação a este problema foi a correção robusta de White, que ajusta os erros padrão a partir da heterocedasticidade do modelo (WOOLDRIDGE, 2010): 
TABELA 6 - Teste pressupostos da regressão

\begin{tabular}{l|r|r|r}
\hline Variável & Normalidade & VIF & 1/VIF \\
\hline HonDiret & 0,83680 & & \\
\hline ROE & 0,95521 & 2,38000 & 0,420005 \\
\hline ROA & 0,96492 & 2,67000 & 0,374807 \\
\hline Lucro & 0,66545 & 1,88000 & 0,530856 \\
\hline Ativo & 0,97858 & 1,51000 & 0,660548 \\
\hline
\end{tabular}

Breusch-Pagan-Godfrey: Prob $>$ chi $^{2}=0,0000$

White: P-value $=5,2 \mathrm{e}-87$

Fonte: Os autores

Em seguida, procedeu-se com o teste robusto para diferenciação de interceptos de grupos e os testes de Breusch-Pagan e Hausman para verificar dentre os modelos de MQO, efeitos fixos ou efeitos aleatórios, o que mais se adequa aos dados da pesquisa:

TABELA 7 - Teste para escolha do modelo

\begin{tabular}{c|c|c}
\hline $\begin{array}{c}\text { Teste robusto para } \\
\text { diferenciar interceptos }\end{array}$ & Teste Breusch-Pagan & Teste de Hausman \\
\hline $\mathrm{H} 0=\mathrm{MQO} / \mathrm{H} 1=\mathrm{EF}$ & $\mathrm{H} 0=\mathrm{MQO} / \mathrm{H} 1=\mathrm{EA}$ & $\mathrm{H} 0=\mathrm{EA} / \mathrm{H} 1=\mathrm{EF}$ \\
\hline $\mathrm{F}(469,1876)=26,71$ & $\begin{array}{c}\text { Qui-Quadrado }(01)= \\
\text { Qui-Quadrado }(03)= \\
12,73\end{array}$ \\
\hline Prob $>\mathrm{F}=0,0000$ & Prob $>$ chibar2 $=0,0000$ & Prob $>$ chibar2 $=0,0127$ \\
\hline
\end{tabular}

Fonte: Os autores

De acordo com os dados acima, nota-se que o modelo mais adequado é o de efeitos fixos, rejeitando-se a hipótese nula a 5\%. Assim, adotou-se a técnica de dados em painel sob o modelo de efeitos fixos com o uso da técnica de regressão com erros-padrão robustos, conforme tabela 8 a seguir. Wooldridge (2010) afirma que o uso de efeitos fixos se justifica em função da análise dos efeitos em cada indivíduo da amostra. Assim, alinha-se com o modelo teórico pois a decisão acerca das políticas de dividendos bem como as métricas de premiação por desempenho ocorrem de maneira distinta em cada empresa.

TABELA 8 - Regressão com Efeitos Fixos e Erros-Padrão Robustos

\begin{tabular}{l|r|r|r|r}
\hline & \multicolumn{1}{|c|}{ Coef. } & Std. Err. & \multicolumn{1}{c}{ t } & P>t \\
\hline Coeficiente & $-3.013 .529,00$ & $409.126,80$ & $-7,37$ & 0,000 \\
\hline ROE & $-32.870,01$ & $21.492,35$ & $-1,53$ & 0,127 \\
\hline ROA & $-243.033,80$ & $99.694,21$ & $-2,44$ & 0,015 \\
\hline Lucro & 0,0065 & 0,0027 & 2,4500 & 0,015 \\
\hline LnAtivo & $209.138,80$ & $24.865,28$ & 8,41 & 0,000 \\
\hline
\end{tabular}

Prob $>\mathrm{F} \quad=0.0000$

R-squared within $=0.1995$ 
R-squared between $=0.5105$

R-squared overall $=0.4849$

Fonte: Os autores

Diante dos resultados encontrados, nota-se que o ROE não apresentou significância estatística. O ROA apresentou significância estatística a 5\%, no entanto, com relação negativa. Os resultados corroboram os achados de Gonzaga, Yoshinaga e Eid Junior (2013). Deste modo, os resultados permitem rejeitar as hipóteses H1 e H2 propostas na pesquisa. Gonzaga, Yoshinaga e Eid Junior (2013) acreditam que uma possível explicação é o fato de que, empresas com maiores retornos poderiam apresentar um maior valor absoluto referente a esses valores. Afirmam ainda que, algumas empresas oferecem um percentual menor sobre um retorno maior, o que poderia resultar em uma remuneração maior em detrimento da situação contrária. Os autores ainda contribuem ao afirmar que as empresas podem utilizar outras medidas de desempenho para avaliação de atuação dos gestores, diferentes de ROE e ROA, e que serviria como base para o estabelecimento dos incentivos.

O lucro apresentou significância estatística e sinal positivo. No entanto, a influência do lucro sobre os pacotes de remuneração executiva no setor de saúde no Brasil é pequena. Assim, os resultados obtidos não permitem rejeitar H3 pois há significância estatística e relação positiva entre o lucro e o total da remuneração no setor. Esses resultados estão alinhados com os achados de Jensen e Murphy (1990a), que, assim como Gonzaga, Yoshinaga e Eid Junior (2013) também identificaram esta relação fraca.

O tamanho da empresa, medido por meio do total do ativo, apresentou forte relação estatística com o pacote de remuneração executiva no setor de saúde. Assim, os resultados não permitem rejeitar $\mathrm{H} 4$ e afirmar que a remuneração executiva é maior em entidades de maior porte, como proposto por Ciscel e Carroll (1980), Gupta (1980), Hall (1987), Murphy (1985) e Gonzaga, Yoshinaga e Eid Junior (2013).

Assim, os achados da pesquisa por meio das regressões apresentadas permitem, em parte, afirmar que os incentivos oferecidos aos gestores de entidades do setor de saúde brasileiro são influenciados pelo tamanho da mesma e estão relacionados com o desempenho econômico destas.

\section{Considerações finais}

O conflito de interesses de gestores e proprietários de empresas é o problema clássico apresentado pela Teoria da Agência. Pesquisadores buscam entender quais as ferramentas que contribuem para o alinhamento desses interesses, a fim de mitigar o problema de agência. Nesse sentido, o presente estudo buscou verificar se há relação entre os incentivos financeiros oferecidos aos gestores e o desempenho das entidades do setor de saúde brasileiro, que prestaram contas junto à Agência Nacional de Saúde Suplementar - ANS no período de 2012 a 2016.

Ao analisar-se medidas de desempenho econômico baseadas em informações contábeis, como o retorno sobre o patrimônio líquido e o retorno sobre os ativos, as evidências do estudo levam a crer que os incentivos oferecidos aos gestores não são afetados por estas medidas. Encontrou-se relação estatisticamente significativa e positiva, porém fraca, com o

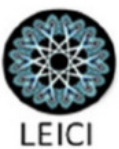


desempenho econômico medido por meio do lucro líquido. Uma das limitações do estudo foi a qualidade da informação: os dados foram extraídos das demonstrações contábeis apresentadas pelas empresas à ANS, puramente contábil. Como sugerem Merchant, Van Der Stede e Zheng (2003), bem como Gonzaga, Yoshinaga e Eid Junior (2013), quando são consideradas medidas de desempenho baseadas em informações do mercado financeiro, como o valor de mercado da ação, a relação estatística se mostra mais forte. Foi possível inferir que o porte da instituição pode influenciar no pacote de remuneração oferecido aos gestores, tal que maiores companhias pagam mais aos seus diretores.

Dentre os resultados encontrados, o fato da remuneração executiva estar relacionada negativamente ao retorno sobre os ativos, pode ser decorrente de que as companhias, no geral, remuneração seus executivos com base em outros indicadores que não o retorno sobre o patrimônio líquido e tampouco o retorno sobre os ativos. Esses resultados estão alinhados com os resultados de Jensen e Murphy (1990a) e Gonzaga, Yoshinaga e Eid Junior (2013).

Assim, os achados contribuem para a literatura ao demonstrarem que o ROE e o ROA não são indicadores utilizados para medir o desempenho de executivos no setor de saúde brasileiro. A pesquisa também contribui ao atestar que o lucro está pouco atrelado à remuneração dos gestores neste segmento e comprovam que há maior remuneração em maiores companhias.

Como sugestão para estudos futuros, pode-se incluir como variável de interesse o indicador de qualidade ranqueado pela própria Agência Nacional de Saúde Suplementar que qualifica os serviços prestados pelas entidades ao público, dado que este indicador também é demonstrado por Sá, Maciel e Reinaldo (2017) como um fator a ser conquistado pela entidade, por meio das ações dos gestores. Também verificar se os achados de Jensen e Murphy (1990a) se aplicam ao setor no Brasil, dado que em seu estudo encontraram relação entre a remuneração e a receita operacional.

Maiores detalhes sobre a remuneração, como o tipo, fixa ou variável, número de membros da diretoria, características da diretoria, como idade, tempo de experiência, qualidade da formação, tempo de atuação na área não foram considerados na pesquisa, o que sugere-se a aprimorar em futuros estudos.

Além disto, no Brasil há a regulação de alguns setores da economia. Assim, também sugere-se que o estudo seja ampliado a outros segmentos, ainda que regulados e que forneçam informações contábeis e de remuneração para o aprofundamento no entendimento dos pacotes de remuneração ofertados aos executivos brasileiros.

\section{Referências}

ANS. Agência Nacional de Saúde Suplementar. < http://www.ans.gov.br/perfil-dosetor/dados-e-indicadores-do-setor/demonstracoes-contabeis $>$. Acesso em 28.06.2017.

ANDERSON, S.; CAVANAHG, J.; HARTMAN, C. Executive excess 2002: CEOs cook books, skewer the rest of us. United for a fair Economy, Aug. 2002.

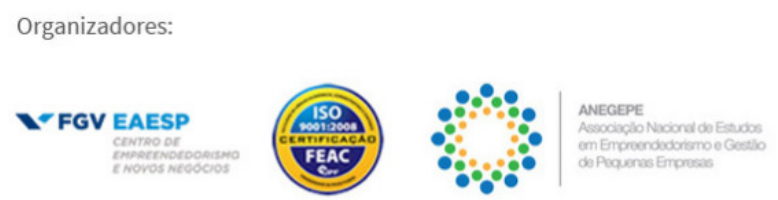

Realizadores:
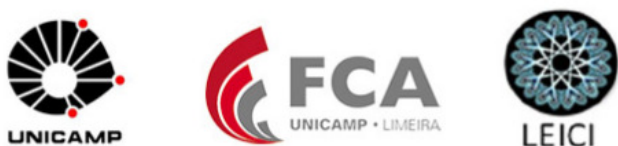
ARAUJO, J. A. O.; PARISI, C.; SILVA, A. F.; NAKAMURA, W. T. Remuneração de executivos e desempenho das companhias abertas brasileiras: uma visão empírica após a publicação da Instrução Normativa CVM 480. Revista Brasileira de Contabilidade, v. 209, p. 68-83, 2014.

ASSAF NETO, A.. Estrutura e análise de balanços: um enfoque econômicofinanceiro. $7^{\text {a }}$ Ed. Editora: Atlas. São Paulo. 2002.

BAKER, M. P.; WURGLER, J. A. Investor sentiment and cross-section of stock returns. The Journal of Finance, v. 61, n. 4, p. 1645-1680, 2006. 1994

BARNETT, V.; LEWIS T. Outliers in statistical data. 3rd edition. J. Wiley \& Sons,

BRITO, Giovani Antonio Silva; MARTINS, Eliseu. Accounting conservatism and the cost of bank credit in Brazil. Brazilian Business Review (English Edition), v. 10, n.

1, p. 27, 2013.

BUSHMAN, R. M.; SMITH, A. J. Financial accounting information and Corporate Governance. Journal of Accounting \& Economics, v. 32, n. 1-3, p. 237-253, 2001.

BYRD, J.; PARRINO, R.; PRITSH, G. Stockholder-manager conflicts and firm value. Financial Analyst Journal, v. 43, n 3, p. 14-30, May/June 1998.

CARVAlHO, G. A saúde pública no Brasil. Estudos Avançados, v. 27, n. 78, 2013

CISCEL, D.H.; CARROL, T.M. "The Determinants of Executive Salaries: an econometric survey". Review of Economics and Statistics, n. 29, p.7-13, 1980.

CONYON, M. J.. Corporate Governance e executive compensation. International Journal of Industrial Organization, v. 15, p. 493-509, 1997.

; GREGG, P.; MACHIN, S. Taking care of business: executive compensation in the United Kingdom. The Economic Journal, Chicago, v. 65, p. 704-714, May, 1995.

; LEECH, D. Top pay, company performance and corporate governance. Oxford Bulletin of Economics and Statistics, Oxford, v. 56, n. 3, p.332 - 351, 1994.

CORDEIRO, J. J.; VELIYATH, R. Beyond pay performance: a panel study of the determinants of CEO compensation. American Business Review, v. 48, n. 12, p. 143-158, 2003.

FILARDI, F.; FREITAS, A. S.; IRIGARAY, H. A.; CAPRA, L. Quinze anos da Agência Nacional De Saúde (ANS): análise do eixo estratégico de articulação e aprimoramento 
institucional na percepção dos especialistas. Revista Ibero-Americana de Estratégia, v. 15, n. 4, p. 105-117, 2016.

FIRTH M. et al. The determinants of top management pay. The International Journal of Management Science, v. 3, n. 2, p. 617-635,1999.

GONZAGA, R. P.; YOSHINAGA, C. E.; EID JUNIOR, W. Relação entre os sistemas de incentivos oferecidos aos gestores e desempenho das empresas brasileiras. Revista Contabilidade Vista \& Revista, v. 24, n. 3, p. 103-118, 2013.

GUPTA, N. Some alternative definitions of size. The Academy of Management Journal, v. 23, n. 4, p. 759-766, 1980.

HALL, B. H. The relationship between firm size and fir growth in the U.S. manufacturing sector. The Journal of Industrial Economics, v. 35, n. 4, p. 583 -606, 1987.

IBGE. Instituto Brasileiro de Geografia e Estatística. < http://www.ibge.gov.br/home/estatistica/populacao/trabalhoerendimento/pnad98/saude/defaul t.shtm >. Acesso em 28.06.2017.

ITTNER, C. D.; LARCKER, D. F.; PIZZINI, M. Performance-based compensation in member-owned firms: an examination of medical group practices. Journal of Accounting and Economics, v. 44, p. 300-327, 2007.

JENSEN, M.; MECKLING, W. Theory of the firm: managerial behavior, agency costs and ownership structure. Journal of Financial Economics, v. 3, n. 4, p. 305-360, 1976.

; MURPHY, K. J. Performance pay and top-management incentives. Journal of political economy, v. 98, n. 2, p. 225-264, 1990a.

; $ـ$ CEO incentives - It's not how much you pay, but how. Harvard Business Review, n. 3, p. 138-153, 1990 b.

; WRUCK, E. G. Remuneration: where we've been, how we got to here, what are the problems, and how to fix them, 2004. Disponível em: <http://ssrn.com/abstract=561305>. Acesso em: 13 jun. 2017.

LEONARD, J. S. Executive pay and firm performance. Industrial \& Labor Relations Review, v. 43, n. 3, p. 13-S-29-S, 1990.

LOEBEL, E.; CARMO, E. Estrutura organizacional: estudo de uma operadora de plano de saúde, modalidade cooperativa médica. Revista de Administração Hospitalar e Inovação em Saúde, v. 13, n. 4, 2016. 
MERCHANT, K. A.; VAN DER STEDE, W. A.; ZHENG, L. Disciplinary constraints on the advancement of knowledge: the case of organizational incentive systems. Accounting, Organizations and Society, n. 28, p. 251 - 286, 2003.

MURPHY, K. J. Corporate performance and managerial remuneration: an empirical analysis. Journal of Accounting and Economics, v7, n. 1, p.11-42, 1985.

Auditing \& Finance, v. 11, n. 3, p. 497-515, 1996.

Reporting choice and the 1992 proxy disclosure rules. Journal of Accounting,

PUKTHUANTHONG, K.; TALMOR, E.; WALLACE, J. S. Corporate governance and theories of executive pay. Corporate Ownership \& Control, v. 1, n. 2, p. 41-62, winter, 2004.

SÁ, M. C.; MACIEL JUNIOR, J. N.; REINALDO, L. M. Processo de ruína finito: um estudo de caso na saúde suplementar no Brasil. Revista Evidenciação Contábil \& Finanças, v. 5, n. 2, p. 88-103, 2017.

WOOLDRIDGE, J. M. Introdução à econometria: uma abordagem moderna. 4. ed. São Paulo: CENGAGE Learning, 2010.

YOSHINAGA, C. E. A relação entre índice de sentimento de mercado e as taxas de retorno das ações: uma análise com dados em painel. 2009. 176f. Tese (Doutorado em Administração) - Universidade de São Paulo - FEA/USP, São Paulo, 2009. 